\title{
Enhanced Historical Limestone Protection by New Organic/Inorganic Additive-Modified Resins
}

\author{
Eleonora Pargoletti ${ }^{1,2 * *(D)}$, Valeria Comite ${ }^{1,2} \mathbb{D}$, Paola Fermo ${ }^{1,2} \mathbb{D}$, Valentina Sabatini ${ }^{1,2}$ and \\ Giuseppe Cappelletti ${ }^{1,2, *(\mathbb{D})}$
}

1 Dipartimento di Chimica, Università degli Studi di Milano, Via Golgi 19, 20133 Milan, Italy; valeria.comite@unimi.it (V.C.); paola.fermo@unimi.it (P.F.); valentina.sabatini@unimi.it (V.S.)

2 Consorzio Interuniversitario per la Scienza e Tecnologia dei Materiali (INSTM), Via Giusti 9, 50121 Firenze, Italy

* Correspondence: eleonora.pargoletti@unimi.it (E.P.); giuseppe.cappelletti@unimi.it (G.C.); Tel.: +39-02-50314228 (G.C.)

Citation: Pargoletti, E.; Comite, V.; Fermo, P.; Sabatini, V.; Cappelletti, G. Enhanced Historical Limestone Protection by New Organic/Inorganic Additive-Modified Resins. Coatings 2021, 11, 73. https://doi.org/10.3390/ coatings 11010073

Received: 22 December 2020 Accepted: 8 January 2021 Published: 10 January 2021

Publisher's Note: MDPI stays neutral with regard to jurisdictional clai$\mathrm{ms}$ in published maps and institutional affiliations.

Copyright: () 2021 by the authors. Licensee MDPI, Basel, Switzerland. This article is an open access article distributed under the terms and conditions of the Creative Commons Attribution (CC BY) license (https:// creativecommons.org/licenses/by/ $4.0 /)$.

\begin{abstract}
The Cultural Heritage deterioration is a spontaneous decay process due to water percolation and air pollutant deposition. In this context, novel acrylic (Twinswet, TW) and siloxane-based (Alpha ${ }^{\circledR}$ SI30) resins were exploited starting from commercial products and then modified by adding either a commercial polysiloxane-based additive (TegoPhobe $1500 \mathrm{~N}$ ) or a precursor of $\mathrm{SiO}_{2}$ nanoparticles (Tetraethyl ortosilicate, TEOS) to improve the Vicenza stone surface hydrophobicity. Properties of the coated materials were studied using different techniques such as water contact angle (WCA), capillary absorption, colorimetric and water vapor permeability measurements. Accelerated UV aging and eight-month outdoor exposure tests (at Milan University campus) were also performed to determine the coatings durability. Notably, the addition of both additives slightly enhanced the surface hydrophobicity resulting in WCAs of about $140^{\circ}$, and decreased the water absorption especially for Alpha-based resins. Conversely, a reduction of water vapor permeability was observed, even if within the threshold value of $50 \%$. Concerning the color variation, Alpha ${ }^{\circledR}$ SI30 preserved the stone external aspect; instead, TW smoothly modified the surface color. All of the studied coatings were stable to both UV aging and outdoor exposure. Hence, the present modified commercial coatings revealed to be very promising for the protection of historical monuments.
\end{abstract}

Keywords: protective coatings; acrylic resins; siloxane resins; hydrophobicity; aging tests; outdoor exposure; Vicenza stone; cultural heritage

\section{Introduction}

Natural stones and marbles have been extensively adopted for the construction of historical monuments. Among these materials, Vicenza stone was used by the major Italian sculptors and architects of the Renaissance and throughout the 1600s, from Palladio to Falconetto, from Sanmicheli to Sansovino. Due to its excellent workability, it was widely exploited in the creation of both sculptural works and architectural parts such as columns, tympanums, stairways for garden furnishings, and statues. In order to preserve the external appearance of these historical monuments, the achievement of a certain degree of surface hydrophobicity represents the main challenge regarding the protection of Cultural Heritage [1-3]. Indeed, the deterioration of stone monuments of historical interest is a spontaneous and irreversible process mainly caused by both water percolation and air pollution $[4,5]$. Specifically, once water and harsh agents enter the stone several physicochemical processes, e.g., carbonate dissolution [6], freezing/thawing cycles [7], and/or crystallization/precipitation [8] can occur, dramatically affecting the quality and properties of stones. Moreover, the action of pollutants on the monuments surface forms dark deposits, the so-called black crusts, mainly present in outdoor areas protected from washouts $[9,10]$. Over time, they can degrade the substrates till almost complete pulverization. In particular, Milan urban area is the most industrialized and densely populated city in the northern 
part of Italy with aerosols that often exceed the limits set by the directive on air quality [11]. The city of Milan suffers from high pollution derived from the intense vehicular traffic, domestic heating, industrial emissions and agricultural activities. Nowadays, $\mathrm{NO}_{x}$ emissions are caused by traffic for $68 \%$, domestic heating for $12 \%$, industries for $9 \%$, and incinerators for $2 \%$. Instead, anthropogenic volatile organic compounds (VOCs) emissions in urban areas are caused by the use of solvents for about $61 \%$ and by traffic for $12 \%$ (from INEMAR, Inventario Emissioni Aria, ARPA Lombardy Region, 2014).

Hence, in order to improve the stones durability, surface hydrophobicity is mandatory. In this context, low-surface-energy coatings combined with the adoption of additives able to enhance surface area (e.g., introducing surface roughness) have already been widely studied [12]. An ideal resin has to be not only a good water-repellent agent but it should also guarantee transparency, durability over time, easiness to remove, and resistance both to UV and bacterial attacks [13-15]. Among the synthesized polymeric coatings, acrylic [16-18], alkyl [19], silane, and siloxane [20-24] resins have been deeply investigated. For instance, Tsakalof et al. [25] evaluated the performances of four synthetic polymers (siloxane-, siloxane/acrylic-, perfluoro ether-, and fluoro-organosilane-based ones) for the protection of several stone substrates, such as marble, travertine, and sandstone. They found that siloxane/acrylic copolymer and polymethylsiloxane seemed to be the optimal ones in terms of surface hydrophobicity and water vapor transpirability. Acrylic-based compounds can also play a key role, thanks to their broad range of useful features, such as transparency, easy film-forming capability, good mechanical properties, and cheap/flexible synthetic processes [26-28]. However, such materials have serious drawbacks, e.g., poor durability, scarce hydrophobicity, and water vapor permeability [24]. Therefore, the addition of ad hoc additives can overcome the previous shortcomings. Some authors of the present paper have already investigated promising Si-based additives adopted as co-adjuvants of siloxane- or silane-polymeric resins $[3,29,30]$. Furthermore, in the last decades, oxidebased nanomaterials have been frequently applied for the restoration and conservation of works of art since they can help to reach surface superhydrophobicity [31]. Lately, both transparent hydrophobic mixed PDMS (polydimethylsiloxane)- $\mathrm{TiO}_{2}-\mathrm{SiO}_{2}$ coatings and $\mathrm{SiO}_{2}$ nanoparticles enriched commercial waterborne mixture of silanes and siloxanes have been proposed for marble/mortar surfaces obtaining very promising results [32,33].

Therefore, starting from both the literature data and our previous results $[29,30]$, we investigated two different organic resins (a polysiloxane- and an acrylic-based ones) to which either an amino functional polysiloxane or $\mathrm{SiO}_{2}$ nanoparticles were added in order to enhance the surface hydrophobicity of Vicenza stone substrates. The surface properties of the coatings and their performances as protective agents were studied using different techniques such as contact angle determination, colorimetric measurements, capillary absorption, water vapor permeability tests, and salt crystallization resistance even after a prolonged outdoor exposure in a real polluted environment (Milan University campus). Finally, the durability and the effect of aging caused by an UV-accelerated aging test will be discussed in detail.

\section{Materials and Methods}

The Vicenza stone specimens were small blocks of about $(2 \times 2 \times 2) \mathrm{cm}^{3}$ or $(5 \times 5 \times 1) \mathrm{cm}^{3}$. They were polished with commercial grade diamond abrasive disks before any hydrophobizing treatment in order to give uniform surfaces and to eliminate possible cutting imperfections; then, they were repeatedly washed with MilliQ water to remove dust deposit and finally dried at room temperature for $24 \mathrm{~h} \mathrm{[31].}$

Vicenza stone is an Oligocene biosparite of backreef zone that forms in the current Berici Hills [34]. It is an organogenic limestone $\left(\mathrm{CaCO}_{3}>90-95 \%\right)$, low in silica and clay component and containing significant amounts of $\mathrm{Al}$ and Fe oxides [34,35]. Indeed, the paleyellow color of Vicenza stone is due to rare oxides and hydroxides dispersed in the matrix. This lithotype has high porosity (open porosity, ca. 23\%) and diffuse micro-porosity [36,37]. The weathering forms visible on the Vicenza stone surfaces are mainly due to dissolution 
and pulverization processes and biological activity; humidity traces and black crusts are often present. The action of rainfall accounts for a significant dissolution of any carbonate rock and, in the case of Vicenza stone, is favored due to its high specific surface [38]; pulverization mainly affects the thin clay layers (particularly montmorillonite) which swell by water absorption, generating high pressures within the rock [34]. The consequence is an irreversible physical decay accompanied by loss of material. The basic agent of all these processes is definitely represented by both surface and capillary waters.

\subsection{Hydrophobic Commercial Coatings and Organic/Inorganic Additives}

Two commercially available resins were used to modify the wettability features of the bare substrates. Alpha ${ }^{\circledR}$ SI30 (purchased by Sikkens, Akzo Nobel, Amsterdam, The Netherlands, labelled as Alpha) is declared to be an oligomeric polysiloxane by the producer; it is colorless, waterproof, and indicated to be used on materials such as plasters and natural stones. In our previous work [31,39], we demonstrated that this resin is composed by a mixture of a trimethoxy silane, where $\mathrm{R}$ could be a quite long chain (i.e., iso-octyl) and a PDMS (polydimethylsiloxane). Hence, Alpha ${ }^{\circledR}$ SI30 could give reticulation thanks to the presence of $-\mathrm{OCH}_{3}$ groups whose oxygen can act as a bridge between two $\mathrm{Si}$ atoms, as already demonstrated by means of infrared spectroscopy by Fermo et al. [39]. The resin was applied as it is without any further dilution. The other adopted commercial resin is Twinswet (by Lantania Srl, Bergamo, Italy, labelled as TW): it is an organic solvent solution of acrylic resins and silicon oils. It is usually used as a protective agent for medium/high absorbent marble, cobblestones and veined stones giving a moderate gloss to the treated surfaces. The resin was applied without any further dilution.

In order to enhance the hydrophobicity features given by the two commercial resins, two additives were added. Specifically, one of organic nature i.e., TegoPhobe 1500N (by Evonik Industries AG, Essen, Germany, labelled as $1500 \mathrm{~N}$ ), an amino functional polysiloxane in ether/isoparaffin solvent was added as received in relatively low amount (10 wt.\% with respect to the quantity of the commercial resins). Concerning the resins-SiO hybrid, it was obtained by mixing Alpha ${ }^{\circledR}$ SI30 or TW with a transparent suspension of $\mathrm{SiO}_{2}$ precursor in a 1:1 ratio (tetraethyl orthosilicate, TEOS, $\geq 99.0 \%$ from Sigma-Aldrich, St. Louis, MO, USA), by exploiting its inorganic in situ hydrolysis once applied to the Vicenza stone substrates.

The application of the coatings on the stone surfaces was carried out by brush in a homogeneous manner, in order to reproduce everyday working conditions, and then the treated samples were dried for $24 \mathrm{~h}$ in an oven at constant temperature $\left(50^{\circ} \mathrm{C}\right)$.

\subsection{Samples Characterizations}

Water static contact angle (WCA) measurements were performed on either bare or coated mortars Vicenza stones by using a Krüss Easy instrument (Hamburg, Germany). A drop of $5 \mu \mathrm{L}$ was gently placed on the surface and the drop profile was extrapolated using an appropriate fitting function depending on the droplets shape. Measurements were repeated at least 15 times to obtain a statistical population especially for bare samples, which were really variable even in the near spots, due to its intrinsic nature.

Coatings homogeneity and the possible $\mathrm{SiO}_{2}$ formation were studied via a Scanning Electron Microscopy (SEM) using a SEM Hitachi TM-1000 Microscope (Hitachi, Tokyo, Japan) coupled with Energy Dispersive X-ray Spectroscopy (EDX; Hitachi ED3000 spectrophotometer, Hitachi, Tokyo, Japan) for elemental analysis. Moreover, to evaluate the roughness of the coated samples, substrates surfaces were investigated by means of a contact profilometer (Bruker DektakXT, Billerica, MA, USA) in a non-contact mode (the latter to prevent possible damage of the stylus). An average value $(<\mathrm{R}>)$ on four different samples segments (of about $2 \mathrm{~mm}$ each) was computed.

Colorimetric analyses were carried out directly on the different areas of the marble surface, before and after the coatings deposition, by means of a Konica Minolta CM 2300d portable spectrophotometer, referring to the CIELab chromaticity diagram and to the 
Normal recommendation $43 / 93$ (1933) [40]. L* is luminosity or lightness, which varies from black (value $=0$ ) to white (value $=100)$; $a^{*}$ ranges from $+a^{*}$ (red) to $-a^{*}$ (green) and $b^{*}$ varies from $+b^{*}$ (yellow) to $-b^{*}$ (blue). The instrument was calibrated with its white reference ( $100 \%$ reflective) and zero calibration box ( $0 \%$ reference) in the $400-700 \mathrm{~nm}$ range. At least five measurements were performed on each area and the mean values of colorimetric parameters were reported. According to the literature, no significant variation occurred when $\Delta E^{*}<5[30,41]$.

Capillary water absorption measurements were performed on bare and coated materials by the gravimetric sorption technique, as described in the standard protocol UNI EN 15801 (conservation of cultural property, test methods, determination of water absorption by capillarity) $[3,30,42]$. In particular, the quantity of the adsorbed water per unit area is determined as reported in the Equation (1).

$$
Q_{\mathrm{i}}=\left(m_{\mathrm{i}}-m_{0}\right) / A
$$

where $m_{\mathrm{i}}$ and $m_{0}$ are the masses of the samples in contact with water at a specific time $t_{\mathrm{i}}$ and at the beginning, respectively, whereas $A$ is the sample area in contact with water during the test. Both the amount of water absorbed at the final time $\left(Q_{\mathrm{ft}}\right)$ and capillary absorption (CA, the curve slope within 30 min of the tests) coefficient were determined, accordingly.

The water vapor permeability (WVP) of bare and coated stones was evaluated by means of the methodology described in the European Standard Norma EN 15,803 [3,43,44]. The reduction of water vapor permeability (RVP) was calculated according to Equation (2).

$$
\% \operatorname{RPV}=\left(\frac{m_{\mathrm{f}, \text { untreated }}-m_{\mathrm{f}, \text { treated }}}{m_{\mathrm{f} \text {,untreated }}}\right) \times 100
$$

where $m_{\mathrm{f} \text {,untreated }}$ and $m_{\mathrm{f} \text {,treated }}$ are the mass of bare and treated sample at the end of the test. It is reported that a polymer material cannot be used as a protective for mineral substrate if RVP exceeds the permitted threshold value (50\%) [45].

\subsection{UV-Accelerated Aging Tests and Outdoor Exposure}

In order to evaluate the stability of the protective coatings, an aging test under UV irradiation (500 W halide lamp, 215-365 nm for $100 \mathrm{~h}$, irradiance specific power of $45.5 \mathrm{~mW} \cdot \mathrm{cm}^{-2}$ ) was performed. After the aging measurements, either water contact angles determination or colorimetric measurements were performed to assess the possible hydrophobicity and color variations.

Finally, the samples were exposed in a typical urban environment in Milan from July 2019 to February 2020. The exposure site was on the Milan University campus (Figure 1), an area not so far from the city center, which is considered representative of a typical urban background [46].

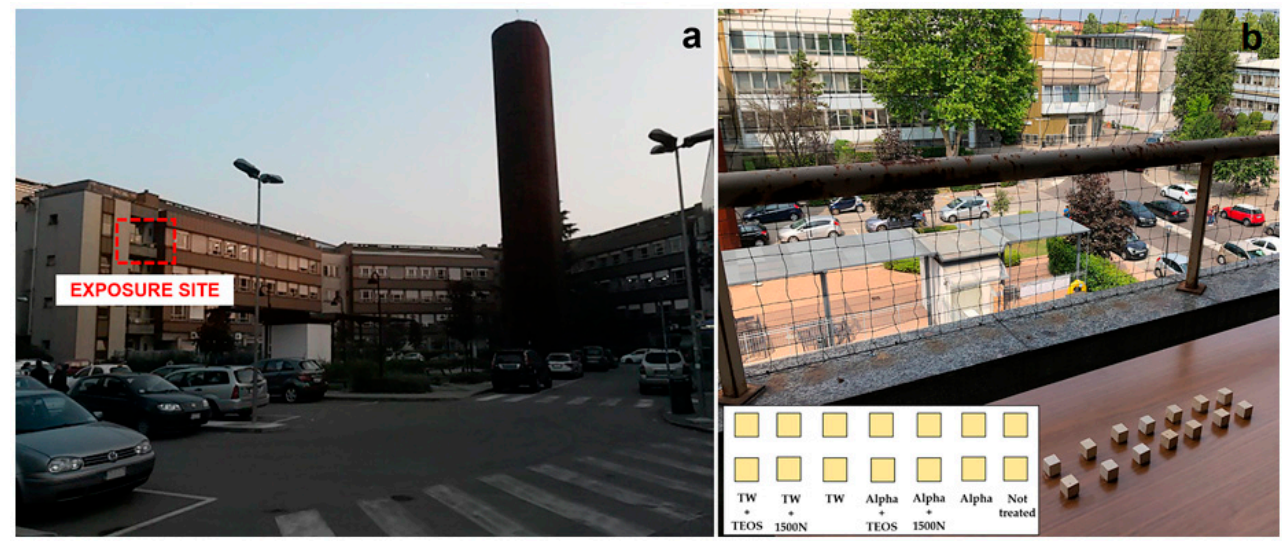

Figure 1. (a) Photo of the outdoor exposure location at University of Milan Campus. (b) Exposure site detail. Insets: on the left, general overview of the exposed specimens while on the right picture of the samples after exposure. 
As clearly reported in the inset of Figure $1 \mathrm{~b}$, a total of 14 samples $(2 \times 2 \times 2) \mathrm{cm}^{3}$ were exposed, i.e., two specimens for bare and each adopted protective. As in the case of UV aging, after the exposure tests, water contact angle measurements and colorimetric measurements were carried out to assess the possible coatings loss in performances.

Moreover, Ion chromatography (IC) was employed for the quantification of the main inorganic constituents of the deposits. About $2 \mathrm{mg}$ of stones powder, collected both on the surface in according with our previous work [3], and $1 \mathrm{~mm}$-in depth from the surface was placed in a test tube and treated with $10 \mathrm{~mL}$ of Milli-Q water. The solutions were put in an ultrasonic bath for $1 \mathrm{~h}$, then centrifuged for $30 \mathrm{~min}$ and injected for IC analyses. Measurements of anionic (mainly $\mathrm{NO}_{3}{ }^{-}, \mathrm{Cl}^{-}$and $\mathrm{SO}_{4}{ }^{2-}$ ) species were carried out by using a Compact IC Flex (Metrohm AG, Herisau, Swisterland) with an IonPac AS14A column (Dionex S.p.a., San Donato Milanese, Italy) using $8 \mathrm{mM} \mathrm{Na}_{2} \mathrm{CO}_{3} / 1 \mathrm{mM} \mathrm{NaHCO}_{3}$, flow rate $=1 \mathrm{~cm}^{3} \times \mathrm{min}^{-1}$, using a conductivity system detector working with an anion selfregenerating suppressor ULTRA (ASRS-ULTRA) (Dionex S.p.A., San Donato Milanese, Italy).

\section{Results and Discussion}

\subsection{Modified Acrylic and Siloxane-Based Protectives Performances}

As previously stated, it is well known that the application of a protective coating can reduce the surface hydrophilicity, thus hindering the degradation of the stones themselves [30]. Therefore, our novel hybrid resins were finely investigated in order to assess their possible high efficacy when applied onto Vicenza stones.

First of all, surface wettability was studied through WCA measurements resulting in a huge increase of the materials hydrophobicity for both Alpha and TW-based coatings with respect to bare specimens (for which the average value is as low as $38 \pm 8$; see Table 1 , 2nd column and Supplementary Video). In particular, for either the two commercial products, a linear rise of WCA values was achieved passing from the pure resin and the one added up with TegoPhobe $1500 \mathrm{~N}$ (around $135^{\circ}$ ) to the TEOS-based ones (WCA up to $138-140^{\circ}$, see also the Supplementary Video).

Table 1. Comparison of water contact angle (WCA), average roughness $(<\mathrm{R}>$ ) water capillary absorption by both the final quantity of water absorbed $\left(Q_{\mathrm{ft}}\right)$ and the capillary absorption (CA) coefficient, reduction percentage of vapor permeability $\left(\%\right.$ RVP) relative to bare and coated Vicenza stone, colorimetric variation assessment $\left(\Delta E^{*}\right)$, either before or after the UV-accelerated aging test. n.d. = not determinable.

\begin{tabular}{|c|c|c|c|c|c|c|c|c|}
\hline \multirow{2}{*}{ Sample } & \multicolumn{6}{|c|}{ Before Aging } & \multicolumn{2}{|c|}{ After Aging } \\
\hline & WCA $\left(^{\circ}\right)$ & $<\mathrm{R}>(\mu \mathrm{m})$ & $Q_{\mathrm{ft}}\left(\mathrm{mg} \cdot \mathrm{cm}^{-2}\right)$ & $\mathrm{CA}\left(\mathrm{mg} \cdot \mathrm{cm}^{-2} \cdot \mathrm{s}^{-1 / 2}\right)$ & \% RVP & $\Delta E^{*}$ & WCA $\left(^{\circ}\right)$ & $\Delta E^{*}$ \\
\hline NT & $38 \pm 8$ & $12 \pm 2$ & 546 & 6.6 & - & - & n.d. & 0.4 \\
\hline Alpha & $134 \pm 4$ & $9 \pm 2$ & 275 & 0.4 & 43 & 3.2 & $130 \pm 5$ & 1.7 \\
\hline Alpha $+1500 \mathrm{~N}$ & $137 \pm 2$ & $14 \pm 1$ & 107 & 0.2 & 46 & 1.4 & $135 \pm 5$ & 1.4 \\
\hline Alpha + TEOS & $140 \pm 4$ & $13 \pm 2$ & 461 & 0.3 & 42 & 4.2 & $125 \pm 6$ & 1.5 \\
\hline TW & $135 \pm 4$ & $10 \pm 3$ & 426 & 0.4 & 26 & 4.6 & $140 \pm 5$ & 0.5 \\
\hline $\mathrm{TW}+1500 \mathrm{~N}$ & $134 \pm 5$ & $12 \pm 4$ & 211 & 0.3 & 30 & 7.4 & $136 \pm 2$ & 2.9 \\
\hline $\mathrm{TW}+\mathrm{TEOS}$ & $138 \pm 2$ & $15 \pm 2$ & 404 & 0.3 & 17 & 4.2 & $132 \pm 1$ & 1.3 \\
\hline
\end{tabular}

Moreover, between the two polymeric families, Alpha-based products seem to be slightly better concerning the hydrophobicity degree reached. The high degree (WCA ca. $140^{\circ}$; see Supplementary Video) achieved by adding TEOS could be ascribable to the hydrolyzation of the tetraethyl groups leading to the formation of $\mathrm{Si}-\mathrm{OH}$ groups and, eventually, $\mathrm{SiO}_{2}$ nanoparticles when exposed to humid air. Therefore, the as-formed hybrid coatings showed an improved hydrophobicity thanks to randomly distributed agglomerates of nanoparticles, which smoothly enhanced the surface roughness. In order to corroborate this hypothesis, SEM/EDX spectroscopy together with profilometer analyses were carried out. Figure S1 displays SEM micrographs of both bare and TW-treated Vicenza stones as representative ones. Notably, two observations can be made: (i) by depositing either pure TW or TW $+1500 \mathrm{~N}$ a similar increase of $\mathrm{Si}$ atomic percentage was obtained 
from EDX (around $6-7 \%$ with respect to $2 \%$ of pristine sample), conversely by adding TEOS a significant rise of silicon content can be noticed (ca. 10\%, inset of Figure S1); (ii) Figure S1d shows well-defined spherical agglomerates of nanoparticles inferring the possible in-situ formation of $\mathrm{SiO}_{2}$, confirming the increase of $\mathrm{Si}$ amount detected by EDX. Furthermore, as reported in Table 1 (3rd column), the bare Vicenza stone exhibits a quite high surface roughness (about $12 \mu \mathrm{m}$ ) that was smoothed by depositing the protective coatings (ca. $10 \mu \mathrm{m}$ ), except for the TEOS-based ones for which a slight increase was noticed (up to $14-15 \mu \mathrm{m}$ ), once again corroborating the in situ formation of nanosized silica particles. In order to deeply evaluate the hydrophobic behavior imparted by the adopted resins, water absorption by capillarity was studied; particularly, both water absorbed after 6 days (quantity at final time, $Q_{\mathrm{ft}}$ ) and the absorption capillary index (CA) were determined and reported in Table 1 (4th and 5th columns), accordingly. As depicted in Figure 2a, the adopted protectives drastically decreased the capillary rise and interestingly, within the first $6 \mathrm{~h}$, only the TW-coated specimen (fuchsia line) absorbed a slightly higher amount with respect to the other samples.
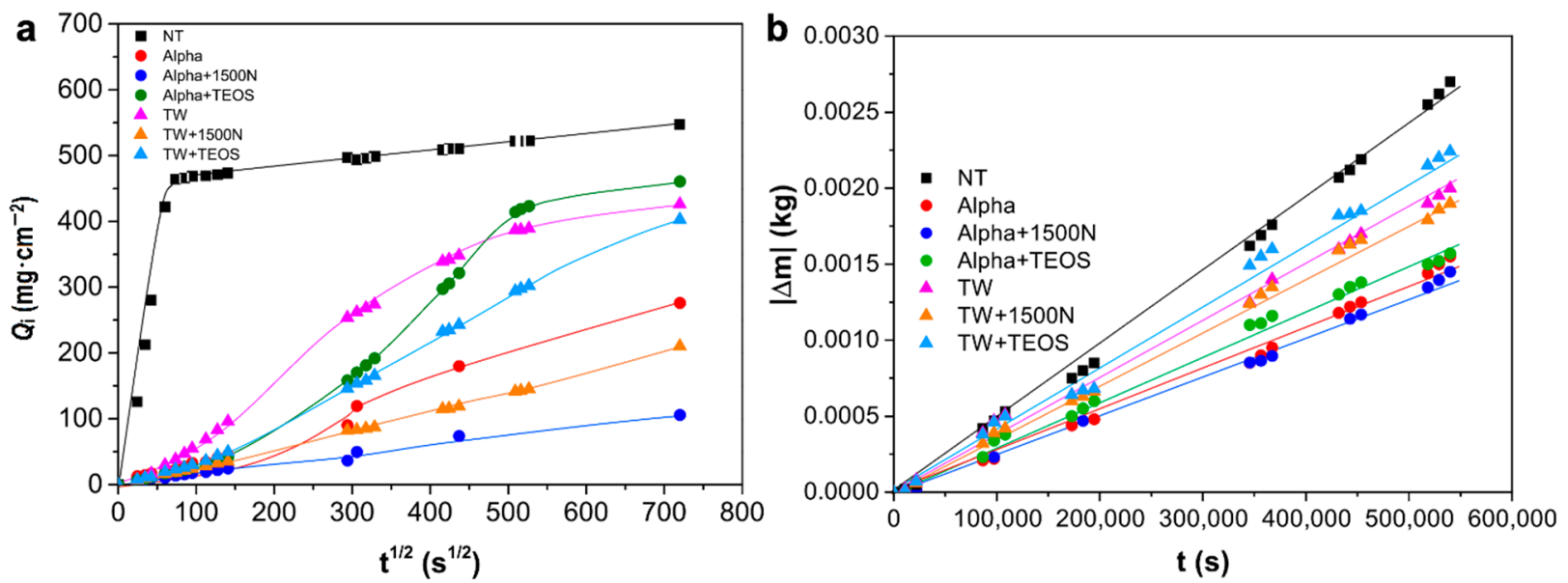

Figure 2. (a) Water capillary absorption curves and (b) water vapor permeability data obtained with both bare (NT) and coated Vicenza stones.

Besides, except for Alpha $+1500 \mathrm{~N}$ and TW $+1500 \mathrm{~N}$, at about half of the test the water amount suddenly rose up. This phenomenon could be due to the intrinsic nature of the Vicenza stone, which is greatly porous (see the Materials and Methods section) and not perfectly homogeneous. As such, the CA indexes calculated at the very beginning of the test (first $30 \mathrm{~min}$ ) are very small (around $0.2-0.4 \mathrm{mg} \cdot \mathrm{cm}^{-2} \cdot \mathrm{s}^{-1 / 2}$ ) and one order of magnitude lower than the pristine sample $\left(6.6 \mathrm{mg} \cdot \mathrm{cm}^{-2} \cdot \mathrm{s}^{-1 / 2}\right.$; see Table 1$)$.

Alongside with the water repellency features, another fundamental parameter to consider is the ability of a protective coating to guarantee the substrate breathability. Therefore, the reduction of vapor permeability was assessed considering the allowed limit of $50 \%$ [45].

Figure $2 \mathrm{~b}$ displays the obtained results. All the investigated resins demonstrated to allow water vapor transpirability, even if the Alpha-family seemed to decrease this feature with respect to TW-one. The computed RVP values were all less than $50 \%$, as clearly visible in Table 1 (6th column). Notably, within the same coating type and especially for TW-family, the addition of TEOS helped the stone breathability since the relative RVP percentages were slightly smaller. According to Zárraga et al. [47], the formation of $\mathrm{SiO}_{2}$ nanoparticles could create small fissures within the polymeric network, resulting in the generation of a secondary capillary system that may improve the stones breathability.

Furthermore, concerning the samples physical appearance, CIELab method was used and, subsequently, $\Delta E^{*}$ parameter was evaluated (Table 1,7 th column). In order to avoid surface color variations, $\Delta E^{*}$ should be lower than 5 . Herein, the only exception was 
$\mathrm{TW}+1500 \mathrm{~N}$ since it had a value of 7.4, probably due to the perceivable surface gloss appearance given by TW product, further increased by the addition of $1500 \mathrm{~N}$ additive.

\subsection{UV-Accelerated Aging Tests and Exposure in a Real Polluted Environment}

In order to evaluate both the coatings stability and their efficacy in preserving the underneath stones from possible degradation, all samples were treated under direct UV lamp irradiations and exposed for about eight months in Milan University campus area, i.e., a real polluted environment (see Figure 1).

Regarding the UV-accelerated aging test, either the water contact angles or the possible surface color modification were assessed. For the former, a general slight decrease of the hydrophobic behavior was observed for Alpha-based and TW + TEOS specimens, conversely the other two TW-coated stones showed a small enhancement (Table 1, 8th column). This negligible loss of hydrophobicity has already been noticed in our previous research work for similar protectives concluding their promising efficacy [3]. On the contrary, the low increase of WCAs for TW and TW $+1500 \mathrm{~N}$ specimens is probably due to the presence of coatings inhomogeneity, nonetheless the computed values are all within the standard deviations range. Besides, $\Delta E^{*}$ parameter was also computed after this test, obtaining very promising results for all the investigated materials. Indeed, all the values are lower than 5 resulting in a not appreciable yellowing effect after the aging process.

Parallelly, outdoor exposure in a real polluted environment was conducted. Specifically, we chose the period between July and February in order to study autumn-winter season that is reported to be the worst one in terms of atmospheric pollution [48]. For the exposed samples, both color variation and salt crystallization resistance were finely investigated to evidence the protective function of the adopted polymers also against environmental pollutants. Figure 3 shows the trend of $\Delta E^{*}$ parameter after this outdoor exposure. Almost all the studied samples exhibited acceptable values (below 5) underlining the absence of any yellowing effect, with the exception of Alpha + TEOS and TW $+1500 \mathrm{~N}$ whose $\Delta E^{*}$ are borderline. The possible increase of this parameter could be attributable to the presence of dirt and impurities on the surface, thus causing a possible appearance modification.

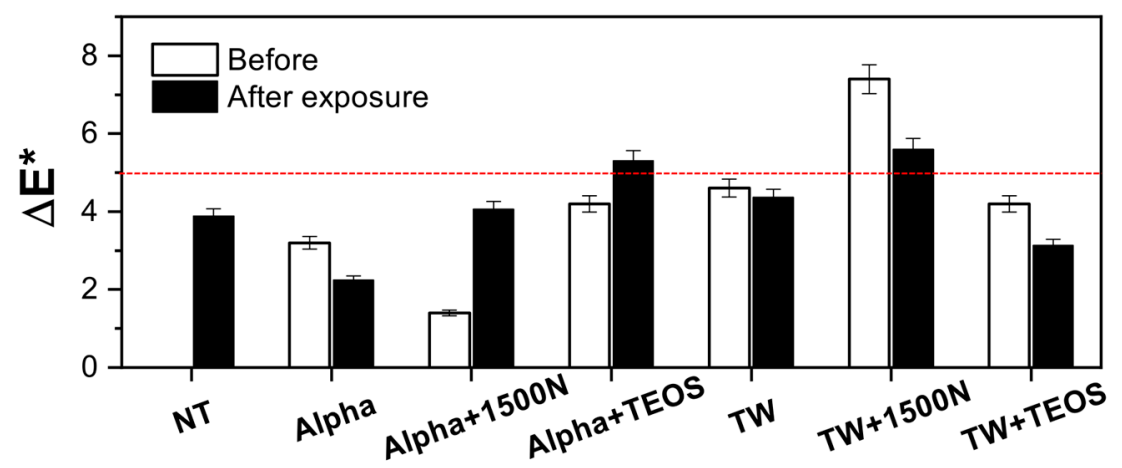

Figure 3. Histogram showing total color variation $\left(\Delta E^{*}\right)$ both before and after outdoor exposure. Dotted red line highlight the threshold value of $5[30,41]$.

As previously stated, the interaction among atmospheric gases and aerosol with stone surfaces is one of the main environmental degradation processes of monuments and historical buildings exposed in polluted environments [11,49]. The gaseous pollutants present in the atmosphere and in particular $\mathrm{SO}_{2}$ are responsible for the degradation process of stone surfaces, together with atmospheric particulate matter (PM) [46]. In particular, the main phenomenon involved is the stone sulphation that leads to the conversion of calcium carbonate into gypsum [50]. Moreover, chloride ions are also due to deposition of PM [51]. Therefore, the interaction between air pollutants and stone can be reduced through the use of effective coatings that prevent degradation processes, limiting the abovementioned anions penetration. 
Herein, ion chromatography (IC) analyses were carried out to investigate both chloride $\left(\mathrm{Cl}^{-}\right)$and sulphate $\left(\mathrm{SO}_{4}{ }^{2-}\right)$ concentrations. Conversely, nitrates $\left(\mathrm{NO}_{3}{ }^{-}\right)$were not considered because bare Vicenza stone lithotype showed a non-negligible concentration of these ions (around $3400 \mu \mathrm{g} \cdot \mathrm{g}^{-1}$ ). Indeed, also considering the possible deliquescence of this species, it is difficult to discern between nitrates intrinsically present in the Vicenza stone and those due to atmospheric pollution. Moreover, in the aerosol particulate matter nitrate is mainly present as ammonium nitrate [52]; for this reason, we also investigated the presence of $\mathrm{NH}_{4}{ }^{+}$and we saw the complete absence of ammonium even in very small concentrations, which further confirms that nitrates come from the stone. Table 2 and Figure 4 display the studied anions concentrations present both on the surface and $1 \mathrm{~mm}$-in depth of the exposed specimens. The surface deposits on the treated samples have higher concentrations with respect to bare (NT) one. Moreover, the lower concentration values of sulphates (Table 2) and chlorides (Figure 4) just below the surface in the not treated specimen, after exposure, can be justified by the fact that these anions tend to dissolve easily, as they are deliquescent, thus penetrating inside the bulk distributing throughout the surface.

Table 2. Concentrations of sulphate ppm $\left(\mu \mathrm{g} \cdot \mathrm{g}^{-1}\right)$ anions relative to the exposed samples and determined by ion chromatography analyses. $\Delta$ is the difference between the two concentrations.

\begin{tabular}{cccc}
\hline \multirow{2}{*}{ Sample } & \multicolumn{3}{c}{ Sulphate Concentration (ppm) } \\
\cline { 2 - 4 } & Surface & 1 mm-in Depth & $\Delta$ \\
\hline NT & $830 \pm 40$ & $460 \pm 20$ & 370 \\
Alpha & $960 \pm 50$ & $460 \pm 20$ & 500 \\
Alpha + 1500N & $2500 \pm 100$ & $430 \pm 20$ & 2070 \\
Alpha + TEOS & $1580 \pm 80$ & $710 \pm 40$ & 870 \\
TW & $1900 \pm 100$ & $1330 \pm 70$ & 570 \\
TW + 1500N & $2600 \pm 100$ & $420 \pm 20$ & 2180 \\
TW + TEOS & $2300 \pm 100$ & $670 \pm 30$ & 1630 \\
\hline
\end{tabular}

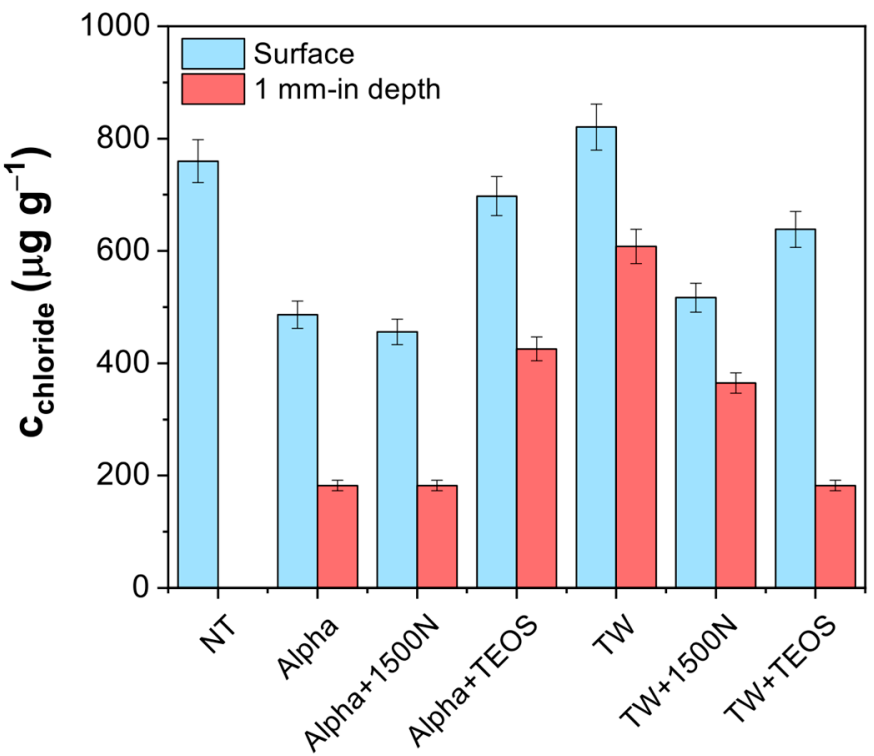

Figure 4. Chloride concentrations ppm $\left(\mu \mathrm{g} \mathrm{g}^{-1}\right)$ determined for the exposed analyzed samples. Each measure was performed in duplicate.

Indeed, as already stated by Comite et al. [53], very porous stones (such as Noto ones that have an average porosity of about $30 \%$, similar to our case of ca. $23 \%$ ) are subjected to easy ions penetration inside the bulk, due to the very high hygroscopicity and, thus, favorable dissolution of especially chloride species. This hypothesis was confirmed by 
the almost absence of $\mathrm{Cl}^{-}$anions at around $1 \mathrm{~mm}$ in-depth from the surface (as depicted in Figure 4).

In order to validate this explanation, the difference $(\Delta)$ between surface and $1 \mathrm{~mm}$ in-depth concentration values was computed and reported in Table 2, accordingly. It is worth noting that Alpha $+1500 \mathrm{~N}$ and TW $+1500 \mathrm{~N}$ seem to be the best performing coatings concerning the creation of a barrier towards atmospheric pollutants, since they possess the highest $\Delta$ values. Therefore, the protective barrier could avoid the salts penetration inside the materials, without changing the samples nature. This outcome is perfectly in line with the water absorption results shown in Figure 2. Indeed, although all the investigated protectives drastically reduce the capillary rise, the highest absorption decrease was noticed with the addition of TegoPhobe $1500 \mathrm{~N}$. Thanks to IC analyses, we corroborated this observation.

Furthermore, in the case of Alpha + TEOS, we obtained a slight increase of the anions concentration in the stones with respect to Alpha and Alpha $+1500 \mathrm{~N}$. Once more, this is probably provoked by the presence of $\mathrm{SiO}_{2}$ nanoparticles that could create small fissures within the polymeric network, as previously stated.

\section{Conclusions}

Herein, we achieved an improvement in terms of hydrophobicity features, substrate breathability, and durability over time by applying two commercially available protectives modified with either a polysiloxane-based additive (TegoPhobe $1500 \mathrm{~N}$ ) or a precursor of $\mathrm{SiO}_{2}$ nanoparticles (Tetraethyl ortosilicate, TEOS) onto porous Vicenza stone. Specifically, the Alpha ${ }^{\circledR}$ SI30 siloxane-based resins seem to perform slightly better with respect to the acrylic Twinswet-based ones. Indeed, the obtained water contact angles (around $140^{\circ}$ ), water vapor permeability (below the threshold value of 50\%), and unperceivable surface color variation, even after both UV-accelerated aging test and prolonged outdoor exposure, were obtained resulting in very promising protectives. Notably, the addition of TEOS resulted in slightly better performances, especially with regard to the hydrophobicity degree reached and smoothly greater transpirability, thanks to the little increase of the surface roughness caused by the presence of in-situ formed $\mathrm{SiO}_{2}$ nanoparticles (as confirmed by both SEM/EDX and profilometry analyses). Furthermore, the addition of TegoPhobe $1500 \mathrm{~N}$ additive led to enhanced protective features in the case of Alpha-based polymers, as previously reported in an our recent paper regarding the hydrophobization of different substrates such as marble and glass materials [29].

As far as the outdoor exposure is concerned, ion chromatography data corroborated the capability of the adopted polymers to guarantee good protective features, forming a barrier that hinders salts to permeate inside the stones through the pores. Especially TegoPhobe $1500 \mathrm{~N}$ additive seems to better form this barrier that was also confirmed by water absorption by capillarity. In this respect, also the addition of TEOS revealed quite promising.

Hence, to the authors' best knowledge, the novel combination of Alpha ${ }^{\circledR}$ SI30 and Twinswet with the two additives has not been reported so far. Moreover, the present research has led to achieve a very high degree of surface hydrophobicity, even with porous materials as Vicenza stone, thus resulting in very promising protectives to be potentially applied for the preservation of the Cultural Heritage.

Supplementary Materials: The following are available online at https:/ / www.mdpi.com/2079-641 2/11/1/73/s1, Figure S1: Scanning Electron Microscopy (SEM) images of (a) bare, (b) TW, (c) TW $+1500 \mathrm{~N}$, and (d) TW + TEOS coated Vicenza stone surfaces; Video: deposition of aqueous methyl orange droplet onto bare Vicenza stone, followed by the same deposition onto Alpha + TEOS treated Vicenza stone.

Author Contributions: Conceptualization, G.C. and P.F.; formal analysis, E.P., V.C. and V.S.; investigation, E.P. and V.C.; data curation, E.P. and V.C.; writing - original draft preparation, E.P. and V.C.; writing - review and editing, G.C. and P.F.; supervision, G.C. All authors have read and agreed to the published version of the manuscript. 
Funding: This research received no external funding.

Institutional Review Board Statement: Not applicable.

Informed Consent Statement: Not applicable.

Data Availability Statement: Data is contained within the article or Supplementary Materials.

Acknowledgments: The use of profilometer, purchased through the Regione Lombardia-Fondazione Cariplo joint SmartMatLab project (Fondazione Cariplo 2013-1766 project), is gratefully acknowledged. The authors gratefully acknowledge Maurizio Fogazzi (ChemArt) for his precious advice concerning TW resin.

Conflicts of Interest: The authors declare no conflict of interest.

\section{References}

1. Mosquera, M.J.; Pinho, L.; Facio, D.S.; Elhaddad, F. New nanomaterials for conservation of cultural heritage: Consolidants, hydrophobic and self-cleaning products. In Science, Technology and Cultural Heritage, Proceedings of the 2nd International Congress on Science and Technology for the Conservation of Cultural Heritage, Sevilla, Spain, 24-27 June 2014; CRC Press: Boca Raton, FL, USA; pp. 121-126.

2. Eyssautier-Chuine, S.; Calandra, I.; Vaillant-Gaveau, N.; Fronteau, G.; Thomachot-Schneider, C.; Hubert, J.; Pleck, J.; Gommeaux, M. A new preventive coating for building stones mixing a water repellent and an eco-friendly biocide. Prog. Org. Coat. 2018, 120, 132-142. [CrossRef]

3. Pino, F.; Fermo, P.; La Russa, M.; Ruffolo, S.; Comite, V.; Baghdachi, J.; Pecchioni, E.; Fratini, F.; Cappelletti, G. Advanced mortar coatings for cultural heritage protection. Durability towards prolonged UV and outdoor exposure. Environ. Sci. Pollut. Res. 2017, 24, 12608-12617. [CrossRef]

4. Varotsos, C.; Tzanis, C.; Cracknell, A. The enhanced deterioration of the cultural heritage monuments due to air pollution. Environ. Sci. Pollut. Res. 2009, 16, 590-592. [CrossRef]

5. Charola, A.E. Salts in the deterioration of porous materials: An overview. J. Am. Inst. Conserv. 2018, 39, 327-343. [CrossRef]

6. Piacenti, F. Chemistry for the conservation of the cultural heritage. Sci. Total. Environ. 1994, 143, 113-120. [CrossRef]

7. Iñigo, A.C.; García-Talegón, J.; Vicente-Tavera, S.; Martín-González, S.; Casado-Marín, S.; Vargas-Muñoz, M.; Pérez-Rodríguez, J.L. Colour and ultrasound propagation speed changes by different ageing of freezing/thawing and cooling/heating in granitic materials. Cold Reg. Sci. Technol. 2013, 85, 71-78. [CrossRef]

8. Fernandes, P. Applied microbiology and biotechnology in the conservation of stone cultural heritage materials. Appl. Microbiol. Biotechnol. 2006, 73, 291-296. [CrossRef]

9. Farkas, O.; Siegesmund, S.; Licha, T.; Török, Á. Geochemical and mineralogical composition of black weathering crusts on limestones from seven different European countries. Environ. Earth Sci. 2018, 77, 1-20. [CrossRef]

10. La Russa, M.F.; Comite, V.; Aly, N.; Barca, D.; Fermo, P.; Rovella, N.; Antonelli, F.; Tesser, E.; Aquino, M.; Ruffolo, S.A. Black crusts on Venetian built heritage, investigation on the impact of pollution sources on their composition. Eur. Phys. J. Plus 2018, 133, 370. [CrossRef]

11. Comite, V.; Fermo, P. The effects of air pollution on cultural heritage: The case study of Santa Maria delle Grazie al Naviglio Grande (Milan). Eur. Phys. J. Plus 2018, 133, 556. [CrossRef]

12. Fadeev, A.Y.; McCarthy, T.J. Self-assembly is not the only reaction possible between alkyltrichlorosilanes and surfaces: Monomolecular and oligomeric covalently attached layers of dichloro- and trichloroalkylsilanes on silicon. Langmuir 2000, 16, 7268-7274. [CrossRef]

13. Doherty, B.; Pamplona, M.; Selvaggi, R.; Miliani, C.; Matteini, M.; Sgamellotti, A.; Brunetti, B. Efficiency and resistance of the artificial oxalate protection treatment on marble against chemical weathering. Appl. Surf. Sci. 2007, 253, 4477-4484. [CrossRef]

14. Rizzarelli, P.; La Rosa, C.; Torrisi, A. Testing a fluorinated compound as a protective material for calcarenite. J. Cult. Herit. 2001, 2, 55-62. [CrossRef]

15. Zhang, J.; Seeger, S. Silica/silicone nanofilament hybrid coatings with almost perfect superhydrophobicity. Chem. Phys. Chem. 2013, 14, 1646-1651. [CrossRef] [PubMed]

16. Carretti, E.; Dei, L. Physicochemical characterization of acrylic polymeric resins coating porous materials of artistic interest. Prog. Org. Coat. 2004, 49, 282-289. [CrossRef]

17. Mazzola, M.; Frediani, P.; Bracci, S.; Salvini, A. New strategies for the synthesis of partially fluorinated acrylic polymers as possible materials for the protection of stone monuments. Eur. Polym. J. 2003, 39, 1995-2003. [CrossRef]

18. Sabatini, V.; Farina, H.; Montarsolo, A.; Pargoletti, E.; Ortenzi, M.A.; Cappelletti, G. Fluorinated polyacrylic resins for the protection of cultural heritages: The effect of fluorine on hydrophobic properties and photochemical stability. Chem. Lett. 2018, 47, 280-283. [CrossRef]

19. Manoudis, P.N.; Karapanagiotis, I.; Tsakalof, A.; Zuburtikudis, I.; Kolinkeová, B.; Panayiotou, C. Superhydrophobic films for the protection of outdoor cultural heritage assets. Appl. Phys. A Mater. Sci. Process. 2009, 97, 351-360. [CrossRef] 
20. Zielecka, M.; Bujnowska, E.; Bajdor, K. Siloxane-containing polymer matrices as coating materials. J. Coat. Technol. Res. 2007, 4, 275-281. [CrossRef]

21. Stewart, A.; Schlosser, B.; Douglas, E.P. Surface modification of cured cement pastes by silane coupling agents. ACS Appl. Mater. Interfaces 2013, 5, 1218-1225. [CrossRef]

22. Rao, Q.; Chen, K.; Wang, C. Facile preparation of self-healing waterborne superhydrophobic coatings based on fluoroalkyl silane-loaded microcapsules. RSC Adv. 2016, 6, 53949-53954. [CrossRef]

23. Atici, E.G.; Kasapgil, E.; Anac, I.; Erbil, H.Y. Methyltrichlorosilane polysiloxane filament growth on glass using low cost solvents and comparison with gas phase reactions. Thin Solid Films 2016, 616, 101-110. [CrossRef]

24. Karapanagiotis, I.; Manoudis, P.N.; Savva, A.; Panayiotou, C. Superhydrophobic polymer-particle composite films produced using various particle sizes. Surf. Interface Anal. 2012, 44, 870-875. [CrossRef]

25. Tsakalof, A.; Manoudis, P.; Karapanagiotis, I.; Chryssoulakis, I.; Panayiotou, C. Assessment of synthetic polymeric coatings for the protection and preservation of stone monuments. J. Cult. Herit. 2007, 8, 69-72. [CrossRef]

26. Dillon, C.E.; Lagalante, A.F.; Wolbers, R.C. Acrylic emulsion paint films: The effect of solution $\mathrm{pH}$, conductivity, and ionic strength on film swelling and surfactant removal. Stud. Conserv. 2014, 59, 52-62. [CrossRef]

27. Ma, C.; Wang, H.; Zhang, H.; Liu, X.; Chen, H. Preparation and Properties of Fluorinated Poly(ethyl methacrylate-co-butyl acrylate). Polym. Sci. Ser. B 2019, 61, 163-169.

28. Zhang, H.; Liu, Q.; Liu, T.; Zhang, B. The preservation damage of hydrophobic polymer coating materials in conservation of stone relics. Prog. Org. Coat. 2013, 76, 1127-1134. [CrossRef]

29. Pargoletti, E.; Motta, L.; Comite, V.; Fermo, P.; Cappelletti, G. The hydrophobicity modulation of glass and marble materials by different Si-based coatings. Prog. Org. Coat. 2019, 136, 105260. [CrossRef]

30. Cappelletti, G.; Fermo, P.; Pino, F.; Pargoletti, E.; Pecchioni, E.; Fratini, F.; Ruffolo, S.A.; La Russa, M.F. On the role of hydrophobic Si-based protective coatings in limiting mortar deterioration. Environ. Sci. Pollut. Res. 2015, 22, 17733-17743. [CrossRef]

31. Cappelletti, G.; Fermo, P.; Camiloni, M. Smart hybrid coatings for natural stones conservation. Prog. Org. Coat. 2015, 78, 511-516. [CrossRef]

32. Chatzigrigoriou, A.; Manoudis, P.N.; Karapanagiotis, I. Fabrication of water repellent coatings using waterborne resins for the protection of the cultural heritage. Macromol. Symp. 2013, 331, 158-165. [CrossRef]

33. Lettieri, M.; Masieri, M.; Morelli, A.; Pipoli, M.; Frigione, M. Oleo/Hydrophobic Coatings Containing Nano-Particles for the Protection of Stone Materials Having Different Porosity. Coatings 2018, 8, 429. [CrossRef]

34. Cattaneo, A.; De Vecchi, G.P.; Pitturi, L.M.; Vitturi, L. Le pietre tenere dei Colli Berici. In Atti e Memorie dell'Accademia Patavina di Scienze, Lettere ed Arti; Accademia Patavina di Scienze: Padua, Italy, 1976; pp. 69-100.

35. Marchesini, B.; Biscontin, G.; Frascati, S. Alterazione delle pietre tenere dei colli Berici. In Atti XXVI Congresso ATI; Associazione Termotecnica Italiana: Rome, Italy, 1972; pp. 1-23.

36. Scrivano, S.; Gaggero, L.; Gisbert Aguilar, J. Micro-porosity and minero-petrographic features influences on decay: Experimental data from four dimension stones. Constr. Build. Mater. 2018, 173, 342-349. [CrossRef]

37. Scrivano, S.; Gaggero, L. An experimental investigation into the salt-weathering susceptibility of building limestones. Rock Mech. Rock Eng. 2020, 53, 5329-5343. [CrossRef]

38. Galan, E. Carbonate rocks; alteration and control of stone quality: Some consideration. In Proceedings of the Atti del I Simposio Internernazionale La Conservazione dei Monumenti nel Bacino nel Mediterraneo, Bari, Italy, 7-10 June 1989.

39. Fermo, P.; Cappelletti, G.; Cozzi, N.; Padeletti, G.; Kaciulis, S.; Brucale, M.; Merlini, M. Hydrophobizing coatings for cultural heritage. A detailed study of resin/stone surface interaction. Appl. Phys. A 2014, 116, 341-348. [CrossRef]

40. NORMAL 43/93 Misure Colorimetriche di Superfici Opache; CNR-ICR: Roma, Italy, 1993.

41. La Russa, M.F.; Ruffolo, S.A.; Rovella, N.; Belfiore, C.M.; Palermo, A.M.; Guzzi, M.T.; Crisci, G.M. Multifunctional TiO 2 coatings for Cultural Heritage. Prog. Org. Coat. 2012, 74, 186-191. [CrossRef]

42. UNI EN 15801. Conservation of Cultural Property. Test Methods. Determination of Water Absorption by Capillarity; UNI: Milan, Italy, 2010.

43. UNI EN 15803. Conservation of Cultural Property. Test Methods. Determination of Water Vapour Permeability; UNI: Milan, Italy, 2009.

44. Manoudis, P.N.; Tsakalof, A.; Karapanagiotis, I.; Zuburtikudis, I.; Panayiotou, C. Fabrication of super-hydrophobic surfaces for enhanced stone protection. Surf. Coatings Technol. 2009, 203, 1322-1328. [CrossRef]

45. Sabatini, V.; Pargoletti, E.; Longoni, M.; Farina, H.; Ortenzi, M.A.; Cappelletti, G. Stearyl methacrylate co-polymers: Towards new polymer coatings for mortars protection. Appl. Surf. Sci. 2019, 488, 213-220. [CrossRef]

46. Fermo, P.; Goidanich, S.; Comite, V.; Toniolo, L.; Gulotta, D. Study and Characterization of Environmental Deposition on Marble and Surrogate Substrates at a Monumental Heritage Site. Geosciences 2018, 8, 349. [CrossRef]

47. Zárraga, R.; Cervantes, J.; Salazar-Hernandez, C.; Wheeler, G. Effect of the addition of hydroxyl-terminated polydimethylsiloxane to TEOS-based stone consolidants. J. Cult. Herit. 2010, 11, 138-144. [CrossRef]

48. Directive 2008/50/EC. Cleaner European Parliament and of the Council of 21 May 2008 on Ambient air Quality and Air for Europe. Available online: https:/ / eur-lex.europa.eu/eli/dir/2008/50/oj (accessed on 9 January 2021).

49. Ausset, P.; Crovisier, J.L.; Del Monte, M.; Furlan, V.; Girardet, F.; Hammecker, C.; Jeannette, D.; Lefevre, R.A. Experimental study of limestone and sandstone sulphation in polluted realistic conditions: The Lausanne Atmospheric Simulation Chamber (LASC). Atmos. Environ. 1996, 30, 3197-3207. [CrossRef] 
50. Comite, V.; Pozo-Antonio, J.S.; Cardell, C.; Randazzo, L.; La Russa, M.F.; Fermo, P. A multi-analytical approach for the characterization of black crusts on the facade of an historical cathedral. Microchem. J. 2020, 158, 105121. [CrossRef]

51. Bernardoni, V.; Vecchi, R.; Valli, G.; Piazzalunga, A.; Fermo, P. PM10 source apportionment in Milan (Italy) using time-resolved data. Sci. Total Environ. 2011, 409, 4788-4795. [CrossRef] [PubMed]

52. Bove, M.C.; Brotto, P.; Calzolai, G.; Cassola, F.; Cavalli, F.; Fermo, P.; Hjorth, J.; Massabò, D.; Nava, S.; Piazzalunga, A.; et al. PM10 source apportionment applying PMF and chemical tracer analysis to ship-borne measurements in the Western Mediterranean. Atmos. Environ. 2016, 125, 140-151. [CrossRef]

53. Comite, V.; Álvarez de Buergo, M.; Barca, D.; Belfiore, C.M.; Bonazza, A.; La Russa, M.F.; Pezzino, A.; Randazzo, L.; Ruffolo, S.A. Damage monitoring on carbonate stones: Field exposure tests contributing to pollution impact evaluation in two Italian sites. Constr. Build. Mater. 2017, 152, 907-922. [CrossRef] 